\title{
Molecular phylogeny and systematics of Calathus Bonelli (Coleoptera: Carabidae: Sphodrini) based on mitochondrial cox1-cox2 sequences
}

\author{
Carlos Ruiz \& José Serrano
}

Ruiz, C. \& Serrano, J. 2006: Molecular phylogeny and systematics of Calathus Bonelli (Coleoptera: Carabidae: Sphodrini) based on mitochondrial cox1-cox2 sequences. - Entomol. Fennica 17: 214-220.

The current subgeneric taxonomy of the genus Calathus is revised according to cox1-cox 2 mitochondrial sequences of 44 species representing six subgenera. The subgenus Calathus s. str. was found to be monophyletic, but the subgenus Neocalathus is clearly polyphyletic and should be split into two or more subgenera. The monotypic subgenus Bedelinus appears in an isolated clade. The recent placement of $C$. rotundatus within the new subgenus Iberocalathus is supported by molecular data, what makes the subgenus Amphigynus to include only the type species $C$. rotundicollis. The species of the $C$. granatensis group are within the sister clade of the subgenus Calathus and should be included in a separate subgenus. Finally, the Canarian subgenera Lauricalathus and Trichocalathus are not well differentiated and do not seem to be monophyletic taxa, which suggests the need for a detailed revision.

C. Ruiz \& J. Serrano, Departamento de Zoología y Antropología Física, Facultad de Veterinaria, Universidad de Murcia, Campus de Espinardo, 30100, Murcia,Spain; E-mail: caruiz@um.es,jserrano@um.es

Received 8 May 2006, accepted 15 June 2006

\section{Introduction}

The genus Calathus Bonelli, 1810 belongs to the tribe Sphodrini and includes many cave, anthropophilic and forest-dwelling specialists in temperate areas. The genus has mainly a Holarctic distribution (a few species are known from Afrotropical Ethiopia and from Neotropical Mexico) and its species are currently separated into several subgenera based on morphological characters (Hovorka \& Sciaky 2003, Lorenz 2005). Most of these subgenera are found in the mainland of the western Palaearctic Region. Calathus s. str. and Neocalathus Ball and Nègre, 1972 are the most species rich. The monotypic subgenus Bedelinus Ragusa, 1885 was ignored by some authors (e.g., Antoine 1957; Zaballos \& Jeanne 1994), and the subgenus Amphyginus Haliday, 1841 was included within Neocalathus by others (e.g., Jeannel 1942). Iberocalathus has been recently proposed by Toribio (2006) to include $C$. rotundatus, an Iberian endemism formerly placed within Amphyginus. Furthermore, some species of uncertain affinities show intermediate characteristics between two or more subgenera. Thus, C. granatensis (Iberian Peninsula) was not included in the subgenus Calathus in the revision of Nègre (1969) but was included in this subgenus by Hovorka \& Sciaky (2003). In the Canary Islands there are two additional subgen- 
era, Lauricalathus and Trichocalathus, which are endemic to the archipelago and coexist with species of Neocalathus (Machado 1992). The pioneering studies of Emerson et al. (1999, 2000) yielded interesting clues about the systematic problems of the genus but the major focus of these studies was on the phylogeography of the Macaronesian taxa.

We undertook a phylogenetic study of the genus based on mitochondrial and nuclear sequences. Our first aim was to examine the agreement between conclusions derived from the analysis of cytochrome-oxidase I-II sequences (cox1-cox2) and the current subgeneric arrangement of the Calathus (sensu lato) for the western Palaearctic taxa. These classifications (i.e., the grouping of particular taxa into subgenera or species-groups) are here considered as initial hypotheses of relationships that can be tested on molecular grounds.

\section{Material and methods}

We have sequenced a cox $1-\operatorname{cox} 2$ fragment that included part of the cox 1 gene and the complete tRNAleu and cox 2 genes. Eighty-four individuals from 44 species of Calathus (Table 1) were included in the analysis. The nucleotide sequences of some species have been taken from Emerson et al. (1999, 2000), mostly corresponding to Macaronesian taxa (EMBL - Nucleotide Sequence Database, accession numbers AJ236944-AJ236980 and AJ404973-AJ405007). The related genera Calathidius, Eutrichopus and Paraeutrichopus were used as an out-group. The species set thus includes representatives of seven recognized Calathus subgenera: Calathus s. str., Neocalathus, Bedelinus, Amphigynus, Iberocalathus, Lauricalathus and Trichocalathus.

Specimens were collected in the localities indicated in Table 1. Beetles were kept alive in the field, immersed in absolute ethanol in the lab and preserved at $+4{ }^{\circ} \mathrm{C}$. DNA was extracted with QIAGEN DNeasy tissue kit (Qiagen, Hilden, Germany) following manufacturer's recommendations. To amplify the mitochondrial COI-COII fragment we used the primers C1-J-2160 5'TAACAGATCGAAATTTAAATACT 3' (designed by Brent Emerson) and TK-N-3782
("Eva", Harrison Laboratory) 5'GAGACCATTA CTTGCTTTCAGTCATCT 3'. These primers amplified a mtDNA fragment of $1706 \mathrm{bp}$. The PCR was carried out in 40 cycles at $94^{\circ} \mathrm{C}$ for 1 min, annealing at $47^{\circ} \mathrm{C}$ for $1 \mathrm{~min}$ and extension of $72{ }^{\circ} \mathrm{C}$ for $2 \mathrm{~min}$. PCR products were purified with isopropanol and $5 \mathrm{M}$ ammonium acetate. Sequencing was performed on an ABI 377 automated sequencer (Applied Biosystems). Internal primers were used to obtain the whole sequence UEA9CAL 5' GTAAATTTAACATTTTTTCCT CAACA 3' and CALCOII 5'TTAAAATCTATT GGTCATCAATGATA 3' (designed by Brent Emerson). Sequences were aligned by eye and incomplete ends were removed from the analysis. The new sequences have been sent to EMBL (accession numbers will be provided within the final version).

The data matrix was subjected to parsimony (MP), Neighbor-Joining (NJ) and Bayesian analyses. The data set was analysed with Modeltest (v. 3.6) (Posada \& Crandall 1998) and the generalized time reversible (GTR) model with gamma distributed among site variation and a proportion of invariable sites was selected as best fit to the data. NJ was performed with this model in PAUP version $4.0 \mathrm{~b} 10$ (Swofford 2002) with 1,000 bootstrap replicates. MP was run in PAUP using heuristic searches with the TBR option. Bayesian analysis was performed with MrBayes v3.1.2 (Ronquist \& Huelsenbeck 2003) consisting in 750,000 generations, sampling trees every 100 th generation.

The log-likelihood scores of sample points were plotted against generation time and stationarity of Markov chains was assumed when the log-likelihood values reached a stable equilibrium. The stationarity of the chains was confirmed by plotting the remaining log-likelihood values (sump command). The equilibrium was attained before the first 1500 trees $(150,000$ generations; burn-in value). The model used was GTR setting among-site rate variation I + gamma.

\section{Results}

The analysed a cox $1-\operatorname{cox} 2$ fragment had $1631 \mathrm{bp}$, of which $603 \mathrm{bp}$ were variable (37\%) and $482 \mathrm{bp}$ were parsimony informative $(80 \%$ of the variable 
Table 1. Species of Calathus included in the molecular analyses; the asterisks show the samples sequenced in this work. $\mathrm{BU}=$ Bulgaria; $\mathrm{Cl}$ = Canary Islands; $\mathrm{GB}=$ Great Britain; IT = Italy; $\mathrm{MO}=$ Morocco; $\mathrm{PL}$ = Poland; $\mathrm{PT}$ = Portugal; SP = Spain.

Taxon

C. (Amphyginus) rotundicollis Dejean

C. (Bedelinus) circumseptus Germar

C. (Calathus) baeticus Rambur

C. (Calathus) fracassii Heyden

C. (Calathus) fuscipes Goeze

C. (Calathus) hispanicus Gautier des Cottes

C. (Calathus) mirei Nègre

C. (Calathus) pirazzolii Putzeys

C. (Calathus?) granatensis Vuillefroy

C. (Calathus?) opacus Lucas

C. (Iberocalathus) rotundatus Jacquelin du Val

C. (Lauricalathus) abaxoides Brullé

C. (Lauricalathus) angularis Brullé

C. (Lauricalathus) angustulus Wollaston

C. (Lauricalathus) appendiculatus Wollaston

C. (Lauricalathus) ascendens Wollaston

C. (Lauricalathus) auctus Wollaston

C. (Lauricalathus) canariensis Harold

C. (Lauricalathus) carinatus Brullé

C. (Lauricalathus) cognatus Wollaston

C. (Lauricalathus) depressus Brullé

C. (Lauricalathus) freyi Colas

C. (Lauricalathus) gomerensis Colas

C. (Lauricalathus) laureticola Wollaston

C. (Lauricalathus) marcellae Colas

C. (Lauricalathus) rectus Wollaston

C. (Lauricalathus) spretus Wollaston

C. (Neocalathus) ambiguus Paykull

C. (Neocalathus) asturiensis Vuillefroy

C. (Neocalathus) cinctus Motschulsky

C. (Neocalathus) erratus C.R. Sahlberg

C. (Neocalathus) gonzalezi Mateu

C. (Neocalathus) melanocephalus Linnaeus

C. (Neocalathus) micropterus Duftschmid

C. (Neocalathus) semisericeus Fairmaire

C. (Neocalathus) simplicicollis Wollaston

C. (Neocalathus) subfuscus Wollaston

C. (Neocalathus?) metallicus Dejean

C. (Trichocalathus) obliteratus Wollaston

C. (Trichocalathus) pilosipennis Machado

C. (Trichocalathus) refleximargo Machado

C. colasianus Mateu (incertae sedis)

C. complanatus Dejean (incertae sedis)

C. vividus Fabricius (incertae sedis)
Sample locality

Soria (SP) *

Murcia (SP) *

Granada (SP) *

Gran Sasso (IT)

1 - Soria (SP) (graecus) *

$2-$ Rif Mountains (MO) (algiricus) *

3 - Gran Sasso (IT)

Barajas (SP)

Soria (SP) *

Gran Sasso (IT)

1 - Cádiz (SP)

2 - Málaga (SP) *

Moyen Atlas (MO)

1 - Braganza (PT) (rotundatus) *

2 - Orense (SP) (rotundatus) *

3 - Serra da Estrela (PT) (estrelensis) *

Tenerife $(\mathrm{Cl})$

Gran Canaria $(\mathrm{Cl})$

Tenerife (Cl)

Gran Canaria $(\mathrm{Cl})$

Tenerife $(\mathrm{Cl})$

Tenerife $(\mathrm{Cl})$

Gran Canaria $(\mathrm{Cl})$

Tenerife $(\mathrm{Cl})$

Gomera $(\mathrm{Cl})$

Tenerife $(\mathrm{Cl})$

Tenerife $(\mathrm{Cl})$

Gomera $(\mathrm{Cl})$

Gomera $(\mathrm{Cl})$

Gomera $(\mathrm{Cl})$

Tenerife $(\mathrm{Cl})$

El Hierro $(\mathrm{Cl})$

Gran Sasso (IT)

Vigo (SP)

Soria (SP) *

Rhodopi Mountains (BU) *

Fuerteventura $(\mathrm{Cl})$

Norfolk (GB)

Poznan (PL) *

Rif Mountains (MO) *

Lanzarote $(\mathrm{Cl})$

Madeira

Pirin Mountains (BU) (aeneus) *

Gomera (Cl)

Gomera (Cl)

Gomera (Cl)

Madeira

Madeira

Madeira 
Table 2. Sequence statistics in Calathus.

\begin{tabular}{lcccccc}
\hline Gen & Sequence length & Variable sites & Informative sites & A & C & G \\
\hline COI & 852 & 324 & 256 & 31.3 & 14.2 & 14.1 \\
tRNAleu & 78 & 19 & 14 & 35.2 & 12.4 & 17.0 \\
COIl & 701 & 309 & 243 & 35.4 & 13.9 & 12.3 \\
Total & 1631 & 660 & 556 & 33.2 & 13.9 & 13.4 \\
\hline
\end{tabular}

sites). The average base composition is shown in Table 2. Trees obtained by Bayesian (Fig. 1), NJ, and MP (Fig. 2) analyses showed the same main clades. (a) Clade 1 includes $C$. rotundatus, a species placed in the subgenus Iberocalathus recently proposed by Toribio (2006).

(b) Clade 2 includes in one branch all the species

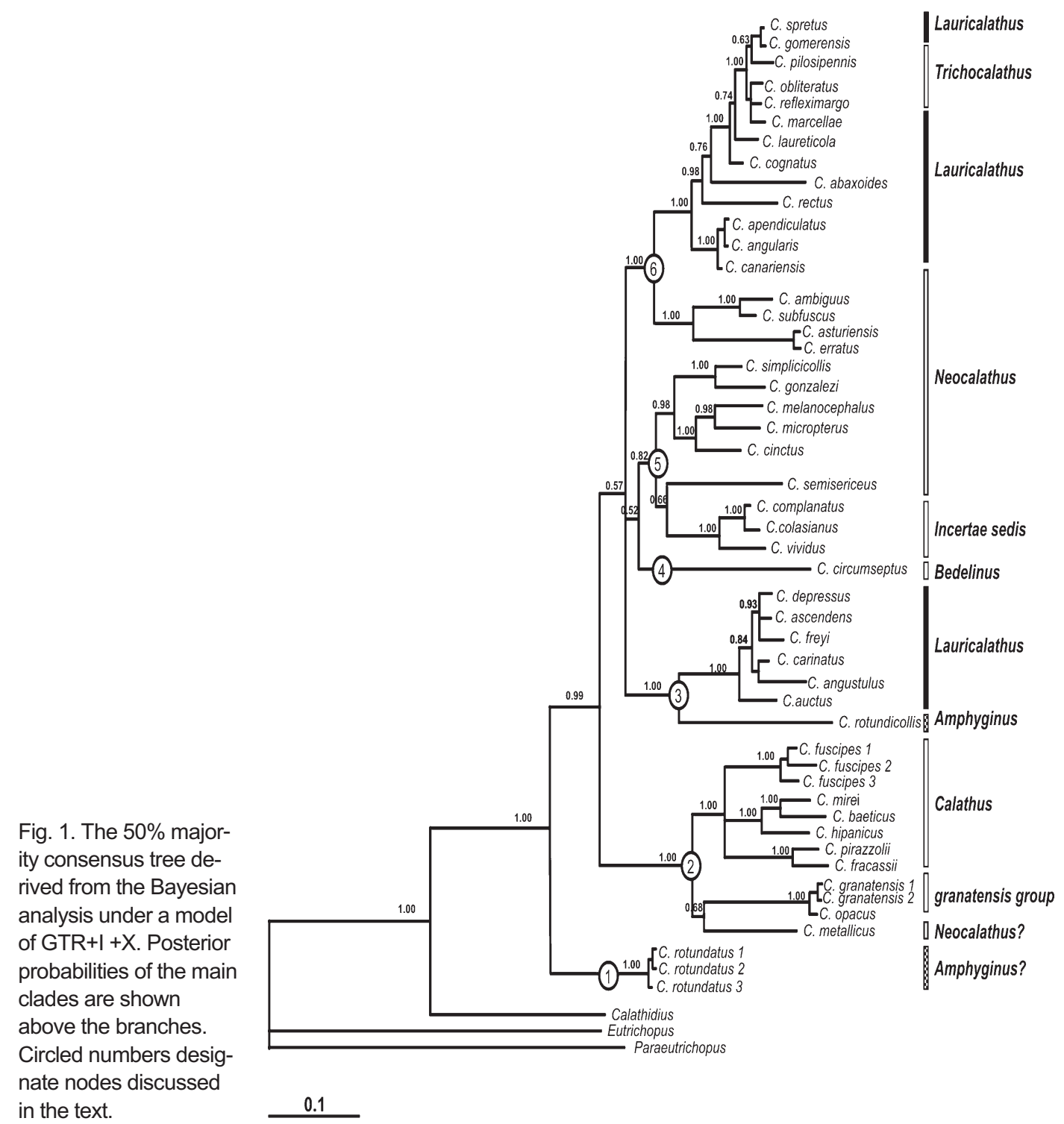




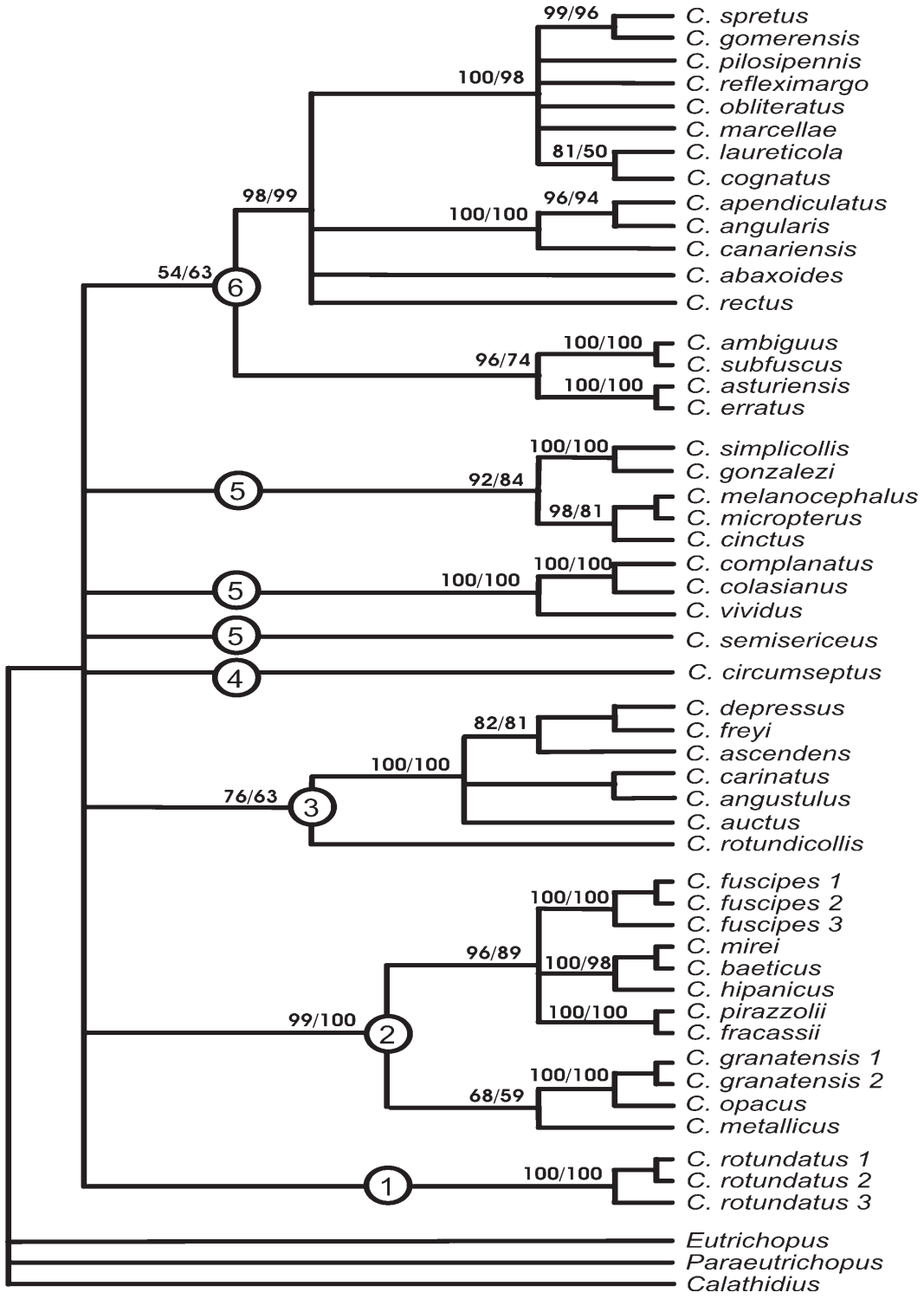

Fig. 2. 50\% majority consensus tree obtained from NeighborJoining (NJ) and Maximum Parsimony (MP) analyses. Numbers above branches correspond to NJ/MP bootstrap values. Circled numbers designate nodes discussed in the text. of the subgenus Calathus and in a second branch C. granatensis $+C$. opacus and C. metallicus, although the relationships of this last species to the granatensis group is weak.

(c) Clade 3 includes $C$. rotundicollis (the type species of the subgenus Amphyginus) and the Tenerifean species of the subgenus Lauricalathus that made up the Clade D in the study of Emerson et al. (2000). This relationship is highly supported in the Bayesian analysis.

(d) Clade 4 includes the single species of subgenus Bedelinus, C. circumseptus. (e) Clade 5 receives less support in the Bayesian analysis and is not recognized in NJ and MP analyses. It includes part of the subgenus Neocalathus (the melanocephalus-group), the species from Madeira C. vividus, C. complanatus and $C$. colasianus, that are placed as incertae sedis in the last Palearctic catalogue and the North African C. semisericeus (Fig. $1)$.

(f) Clade 6 includes the other species of the subgenus Neocalathus (the ambiguus group) and the Canarian taxa belonging to the subgenera 
Lauricalathus and Trichocalathus that made up the Clade C of Emerson et al. (2000).

\section{Discussion}

The molecular data corroborate the separation of the subgenus Iberocalathus (Toribio 2006), described on the basis of morphological and geographic data. This monotypic subgenus includes C. rotundatus, a species formerly included in the subgenus Amphyginus by Hovorka \& Sciaky (2003). Therefore this last subgenus only includes the European $C$. rotundicollis that is related to the clade D of Emerson et al. (2000). This clade is made up by the depressus-group inhabiting Tenerife. This finding suggests that the clade D of Emerson et al. (2000) has a Continental ancestor related to $C$. rotundicollis.

The subgenus Calathus, here represented by the widespread and polytypic $C$. fuscipes and 5 taxa endemic to Iberia and Italy, is a monophyletic taxon that is in accordance with the delimitation of the subgenus put forward by Nègre (1969) on morphological grounds: the number of elytral punctures, the shape of the apical tip of median lobe and the presence of a distinct spine in the internal sac of aedeagus. Its sister taxon is the granatensis-group.

The relationship of $C$. granatensis $+C$. opacus to C. (Neocalathus) metallicus was not previously suspected and suggests that the affinities of the last species must be assessed by considering different character sets. The uncertain position of the siblings $C$. granatensis and $C$. opacus, formerly assigned to Calathus s. str., has been solved to some extent as the molecular data suggest that they should be better placed in a subgenus of their own. In fact, the diagnostic characters of the subgenus Calathus s. str. are not found in the C. granatensis group.

The relationships of the monotypic subgenus Bedelinus have not satisfactorily solved, as it only appears weakly related to some Neocalathus taxa in the Bayesian analysis (clade 5).

The subgenus Neocalathus is polyphyletic as some species are related to Lauricalathus and Trichocalathus (clade 6, Figs. 1-2), whereas other species make a monophyletic group with Continental and Macaronesian taxa (clade 5).
Further, C. metallicus is not related to the above mentioned lineages but to the $C$. granatensis group (clade 2). These results suggest that the taxonomy of Neocalathus should be thoroughly revised. The species of Neocalathus are currently characterised by preference for open habitats and a good dispersal power based on the development of functional wings. These features are congruent with the hypothesis of a close relationship between particular Macaronesian and Neocalathus taxa [C. subfuscus and C. ambiguus; C. simplicicollis $+C$. gonzalezi and the $C$. melanocephalus group; Emerson et al. (2000)].

Finally, the subgenus Lauricalathus is polyphyletic as it is divided between clades 3 and 6 (Figs. 1-2). Clade 3 is made up by the depressusgroup of Tenerife, whereas clade 6 includes the other species of Lauricalathus plus the three species of the subgenus Trichocalathus, C. obliteratus, $C$. pilosipennis and $C$. refleximargo inhabiting La Gomera. The scarce differentiation of Trichocalathus in relation to the species of Lauricalathus also present in La Gomera shows the need of further molecular analyses for a better assessment of its taxonomic validity. The species of the depressus-group must be kept within Lauricalathus (C. depressus is the type species of the subgenus), whereas the other species of the subgenus (the clade $\mathrm{C}$ of Emerson et al. 2000) should be eventually included in a new subgenus.

Acknowledgements. This study has been supported by the project 00595/PI/04, of the Fundación Seneca, Consejeria de Educación de Murcia. Thanks are due to Brent Emerson (Norwich) for lab facilities, sequence data and valuable opinions. Our colleagues Jose Luis Lencina and Carmelo Andújar helped in collecting some of the species included in this study. Pilar de la Rúa, J. Fermín Sánchez-Gea and Jesús Gómez-Zurita made valuable comments that have much improved the final draft. Likewise, two anonymous referees and Matti Koivula made also valuable comments. We thank M. Koivula for taking over the editorial responsibilities for this paper.

\section{References}

Antoine, M. 1957: Coléoptères Carabiques du Maroc (2ème partie). - Mémoires de la Société des Sciences Naturelles et Physiques du Maroc (N.S. Zoologie) Rabat 3: 178-314. [In French.]

Emerson, B. C., Oromí, P. \& Hewitt, G. M. 1999: MtDNA phylogeography and recent intra-island diversifica- 
tion among Canary Island Calathus beetles. - Molecular Phylogenetics and Evolution 13: 149-158.

Emerson, B. C., Oromí, P. \& Hewitt, G. M. 2000: Interpreting colonization of the Calathus (Coleoptera: Carabidae) of the Canary Islands and Madeira through the application of the parametric bootstrap. - Evolution 54: 2081-2090.

Hovorka, O. \& Sciaky, R. 2003: Tribe Sphodrini (pars). In: Löbl, I. \& Smetana, A. (eds.), Catalogue of Palaearctic Coleoptera. Vol. 1. Archostemata, Myxophaga, Adephaga: 521-532. Apollo Books, Stenstrup. 819 pp.

Jeannel, R. 1942: Coléoptères Carabiques. — Faune de France 40: 572-1173. Lechevalier, Paris. [In French.]

Lorenz, W. (ed.) 2005: Systematic list of extant ground beetles of the World. - Author's edition, Tutzing. $530 \mathrm{pp}$.

Machado, A. 1992: Monografía de los carábidos de las Islas Canarias (Insecta, Coleoptera). — La Laguna: Instituto de Estudios Canarios, 734 pp. [In Spanish.]
Nègre, J. 1969: Los grandes Calathus de la Península Ibérica. - Miscel.lanea Zoológica 2 (4): 7-32. [In Spanish.]

Posada, D. \& Crandall, K. A. 1998: Modeltest: testing the model of DNA substitution. - Bioinformatics 14: $817-818$.

Ronquist, F. \& Huelsenbeck, J. P. 2003: MRBAYES 3: Bayesian phylogenetic inference under mixed models. - Bioinformatics 19: 1572-1574.

Swofford, D. L. 2002: PAUP*: Phylogenetic Analysis using Parsimony. Version 4.0b. Sinauer Associates, Sunderland.

Toribio, M. 2006: Notas sobre el género Calathus Bonelli, 1810, en la Península Ibérica (Coleoptera, Carabidae). - Bulletin de la Société Entomologique de France 111: 51-57. [In Spanish.]

Zaballos, J. P. \& Jeanne, C. 1994: Nuevo catálogo de los carábidos (Coleoptera) de la Península Ibérica. Monografías de la Sociedad Entomológica Aragonesa 1, Zaragoza. 159 pp. [In Spanish.] 